Uluslararası Sosyal Bilgilerde Yeni Yaklașımlar Dergisi,2020, 4(1), 62-78

International Journal of New Approaches in Social Studies, 2020, 4(1), 62-78

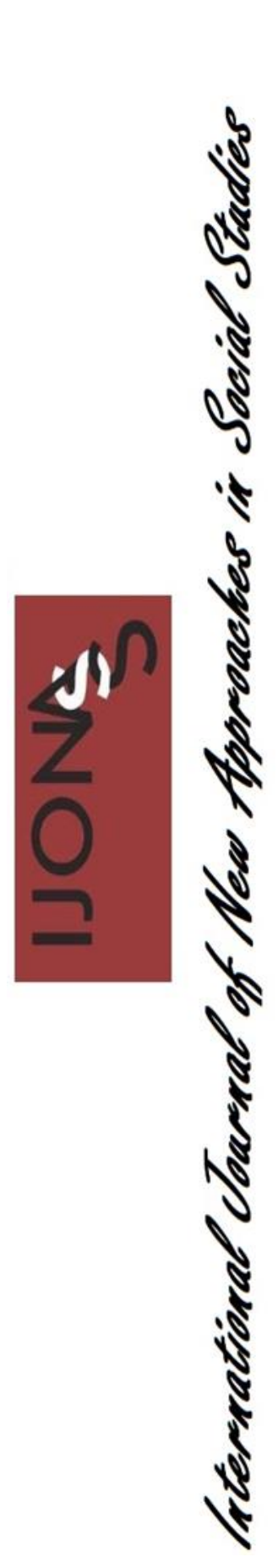

\title{
Sosyal Bilgiler Öğretmen Adaylarının Çevre Sorunlarına Yönelik Farkındalıklarının İncelenmesi*
}

\author{
Y1ldıray KARADAĞ ${ }^{1 * *} \&$ Fatih $\operatorname{ACAR}^{2}$
}

Gönderilme Tarihi:25 Şubat 2020

Kabul Tarihi: 29 Nisan 2020

DOI: $10.38015 /$ sbyy. 693956

\begin{abstract}
$\ddot{O}_{z:}$
Çevre içinde insanın veya herhangi bir canlının yaşadı̆̆ı, hayati bir ilişki ile bağglı olduğu yerdir. Fakat özellikle son yüzyllda, insanoğlunun farklı beşerî ve ekonomik etkinliklerine dayal olarak doğal çevreyi tahrip etmesi ve kirletmesi sonucunda çevre sorunları çok boyutlu ve karmaşık bir hal almıştır. Çevre sorunlarının azaltılması için ise birçok ülke tarafindan farklı uygulamalar yapılmaktadır. Bu uygulamaların en önemlilerinden biride eğitimler aracılı̆̆ıyla bireylerin çevre sorunlarına yönelik farkındalıklarının artırılmasıdır. Bu kapsamda ülkemizde ilköğretim kademesinde yer alan sosyal bilgiler dersi, gelecek nesillerin çevre sorunlarına yönelik yeterli bilgiye sahip olabilmesi ve çevre sorunlarına yönelik farkındalık düzeylerinin artırllması açısından önemli bir yere sahiptir. Kuşkusuz ilköğretim kademesinde yer alan ögrencilerimize bu bilgilerin aktırlması veya çevre sorunlarına yönelik farkındalı̆̆ın kazandırılması için öncelikle ögretmenlerimizin ve öğretmen adaylarımızın çevre konularında bazı yeterliklere sahip olması gerekmektedir. Bu kapsamda bu araştırmada sosyal bilgiler ögretmen adaylarının çevre sorunlarına yönelik farkındalıklarını incelemek amaçlanmıştır. Araştırmada nicel araştırma yöntemlerinden tarama modeli kullanılmuştır. Araştırmanın çalışma grubunu 2019-2020 güz döneminde Ondokuz Mayıs Üniversitesi ve Kastamonu Üniversitesi Eğitim Fakültelerinde öğrenim gören 240 sosyal bilgiler ögretmen adayı oluşturmuştur. Veriler Güven ve Aydoğdu (2012) tarafindan geliştirilen "Çevre Sorunlarına Yönelik Farkındalık Ölçeği" ile toplanmıştır. Araştırma verilerinin analizinde frekans, yüzde, aritmetik ortalama, standart sapma, Mann Whitney-U ve Kruskal Wallis Testi kullanılmıştır. Araştırma sonucunda sosyal bilgiler ögretmen adaylarının çevre sorunlarına yönelik yüksek düzeyde farkındalı̆̆a sahip olduğu tespit edilmiştir. Ayrıca ögretmen adaylarının çevre sorunlarına yönelik farkındalıklarının cinsiyet, sınıf düzeyi, yaşadığl yerde çevre sorunu olma durumu ve çevre sorunlarına yönelik ders alma durumu değişkenlere göre farklılaşmadı̆̆ sonucuna ulaşılmıştır. Öğretmen adaylarının çevre sorunlarına yönelik seminer, toplantı veya kongrelere katılma durumu değişkenine göre ise seminer, toplantı veya kongrelere katılan ögretmen adayları lehine anlamlı bir farklılı̆̆ın olduğu tespit edilmiştir. Bu doğrultuda seminer, toplantı veya kongrelere katılan öğretmen adaylarının daha yüksek düzeyde çevre sorunlarına yönelik farkındalığa sahip olduğu söylenebilir.
\end{abstract}

Anahtar Kelimeler: Çevre sorunları, çevre eğitimi, farkındalık, sosyal bilgiler öğretmen adaylart.

\footnotetext{
${ }^{1}$ Ondokuz Mayıs Üniversitesi, Türkiye. Orcid ID: 0000-0002-0336-7815

${ }^{2}$ Kastamonu Üniversitesi, Türkiye. Orcid ID: 0000-0002-8694-4883

"Bu makalenin bir kısmı, II. Uluslararası Coğrafya Eğitimi Kongresi’nde sözlü bildiri olarak sunulmuştur.

${ }^{* *}$ Sorumlu Yazar (Corresponding Author): yildiray.karadag@ omu.edu.tr
} 


\begin{abstract}
:
The environment is a system in which people and other living things live and with which they establish a vital connection. However, human and economic activities especially in the last century have been damaging the environment, making environmental issues more multidimensional and complicated. Many countries implement a variety of policy interventions to resolve environmental issues. One of the most important of those interventions is to raise people's awareness of environmental issues through education. The primary social studies course in Turkey plays a key role in informing future generations about environmental issues and raising their awareness of them. Teachers and preservice teachers should first possess environmental competence to be able to inform students about environmental issues and raise their awareness of them. The aim of this study was to determine preservice social studies teachers' awareness of environmental issues. Screening model, which is a quantitative research method, was used. The study sample consisted of 240 social studies students of the Education Faculties of Ondokuz Mayls University and Kastamonu University in the 2019-2020 fall semester. Data were collected using the Scale of Awareness of Environmental Issues developed by Güven and Aydoğdu (2012). Data were analyzed using frequency, percentage, arithmetic mean, standard deviation, and Mann Whitney-U and Kruskal Wallis tests. Results showed that participants were highly aware of environmental issues and that their level of awareness did not differ by gender, grade level, experiencing environmental issues where they live, and having taken courses on environmental issues. However, participants who attended seminars, meetings or conferences were more aware of environmental issues than those who did not.
\end{abstract}

Keywords: Environmental problems, environmental education, awareness, preservice social studies teachers.

\title{
GÍRIŞ
}

Canlı yaşamı için en önemli kavramlardan biri olan çevre; içinde insanın veya herhangi bir canlının yaşadığı, bu canlıların hayati bir ilişki ile bağlı olduğu, farklı şekillerde etkilediği ve etkilendiği bir yer olarak ifade edilebilir (Özey, 2001; Y1ldız, Sipahioğlu ve Y1lmaz, 2005). Bu ortak yaşantıya ve canlı yaşamına zarar veren, doğal dengeyi bozan her türden problemler ise çevre sorunları olarak adlandırılabilir. Çevre sorunları özellikle son yüzyılda, insanoğlunun farklı beşeri ve ekonomik etkinliklere dayalı olarak doğal çevreyi tahrip etmesi, kirletmesi hatta doğal çevrenin yapısını bozarak yeni yapay alanlar oluşturması nedeniyle çok boyutlu ve karmaşık bir hal almıştır (Atasoy, 2006). Dünya bu zaman diliminde, her yıl yüzlerce hayvan ve bitki türünün neslinin tükendiği, açlık veya elverişsiz sağlık koşulları yüzünden her yıl yaklaşı 13,5 milyon çocuğun öldüğü, yeryüzünde yaşayan toplam nüfusun yarısının içme suyu bulma konusunda zorluk yaşadığ 1 , iklim değişikliklerinin bir sonucu olarak birçok kara parçasının su altında kalma tehlikesi geçirdiği, tropikal ormanların yok olduğu ve çölleşmenin arttığı bir yere dönüşmüştür (Özey, 2001). Bütün bu nedenlerden dolayı yerküre son yüzyılda tarihte hiç olmadığı kadar kirlenmiş ve çevre sorunları küresel bir hal almıştır (Köylü, 2011; Özey, 2001b).

Çevre sorunları ile başı dertte olan ülkeler ise çevre sorunları konusunda büyük bir çıkmazın içerisine sürüklenmiştir (Özey, 2001). Yaşanan olumsuz gelişmeler neticesinde 1970'li yıllarda dünyanın siyaset, eğitim ve bilim gibi alanlarının önde gelen isimleri çevre sorunlarının çözümüne önem vermeye başlamış ve çeşitli adımlar atmışlardır (Balkan Kıyıcı, 2009). Bu adımların ilki 1970 yılının çevre sorunlarının artışına dikkat çekmek için doğa koruma yılı olarak kabul edilmesidir. Ardından Birleşmiş Milletler tarafından 1972 yılında ilk Uluslararası Çevre Konferansı ve 1977 yılında Hükümetler Arası Çevre Eğitimi Konferansları düzenlenmiştir. Daha sonra 1979'da Birleşmiş Milletler I. Dünya İklim Konferansı, 1982 yılında ise Kenya-Nairobi'de Birleşmiş Milletler Çevre ve Kalkınma Konferansı düzenlenmiştir. 1987' de ise “Ortak Geleceğimiz” isimli Brundland Raporu yayınlanmış ve 1990’da II. Dünya İklim Konferansı yapılmıştır. Devam eden yıllarda 1992'de Brezilya-Rio de Jenerio'da, 1997'de Japonya-Kyoto'da, 2000'de Hollanda-Lahey'de benzer nitelikte 
konferanslar ve toplantılar yapılmıştır. 2002 yılında da Birleşmiş Milletler Sürdürülebilir Kalkınma Konferansı düzenlenmiştir (Karatekin, Kuş ve Merey, 2014; Özey, 2001; Yıldız ve ark., 2005). Yapılan bu toplantılar, konferanslar veya anlaşmalar neticesinde çevre sorunlarını önlemek ve çözmek için birçok karar alınmış ve raporlar yayınlanmıştır.

Türkiye Cumhuriyeti Devleti'nin çevre sorunlarına yönelik ilk çözüm arayışları da bu gelişmelere paralel olarak 1970'li yıllara kadar uzanmaktadır. Zira Türkiye Cumhuriyeti Devleti'nin üzerinde bulunduğu coğrafyada yaşadığı çevre sorunları diğer ülkelerden farklı değildir. Özellikle büyük şehirler olan İstanbul, Ankara, İzmir, Adana, Bursa, gibi illerdeki hava kirliliği oranlarının yüksekliği (Türk Mühendis ve Mimar Odaları Birliği Çevre Mühendisleri Odası, 2018), bilinçsiz ve yanlış kullanım nedeniyle tarım arazilerinin erozyon tehlikesi altında olması, denizlerin ve tatlı su kaynaklarının büyük bir kısmının evsel veya sanayi atıkları, çöpleri ve yanlış kullanımlar nedeniyle kirlenmesi Türkiye Cumhuriyeti Devleti'nin karşı karşıya kaldığ 1 en büyük çevre sorunları arasında yer almaktadır (Özey, 2001b). Bütün bu sorunların varlığı nedeniyle Türkiye Cumhuriyeti Devleti 1970'li yıllarda uluslararası alanda gerçekleştirilen birçok konferansa katılmış ve çevre sorunlarına yönelik anlaşmalarda taraflar arasında yer almıştır. Bunun yanında 1982 Anayasa'sının 56. maddesinde çevre sorunlarını önlemenin vatandaşların ve devletin sorumluluğunda olduğu ve tüm bireylerin sağlıklı, dengeli bir çevrede yaşama hakkına sahip olduğu vurgulanmıştır (Türkiye Büyük Millet Meclisi, 1982). Bu madde 1şığında ülkemizde çevre koruma adına sıfır atık projesi, çevre dostu projesi, emisyon kontrolünün geliştirilmesi, binalarda enerji kimlik belgesi, atık yönetim uygulaması, çevre referans laboratuvarı gibi projeler ve uygulamalar gerçekleştirilmektedir (Çevre ve Şehircilik Bakanlığ 1,2018$)$.

Türkiye'de ve birçok ülkede bu uygulamaların yanında çevre sorunlarının çözümü için alternatif arayışlarda devam etmektedir. Bunlardan bazıları para cezaları, çevre koruma örgütlerinin kurulması, koruyucu ve caydırıcı önlemler, alternatif enerji kaynaklarıdır. Fakat bu tedbirlerden hiçbiri çevre sorunlarının gerçek çözümü olan çevreye karşı duyarlı insanlar yetiştirmek kadar önemli değildir (Özey, 2001). Çünkü yaşanılabilir bir çevre oluşturmak için öncelikle o toplumda yaşayan bireylerin çevresel farkındalıklarının geliştirilmesi gerekir. Bu sağlandıktan sonra bireylerin çevre sorunlarına yönelik önlemler alması olanaklı bir hale dönüşecektir. Özellikle de gençlerin çevreyi koruma konusunda bilinçlendirilmesi sürdürülebilir bir gelecek için büyük öneme sahiptir (Özbebek Tunç, Akdemir Ömür ve Düren, 2012). Bu amaçlar doğrultusunda çevre eğitimi insanlarda gerekli biliş, duyuş ve davranış değiştirmenin başlıca yolu olarak gitgide önem kazanmaktadır (Özdemir, 2007).

Çevre eğitimi, insanoğlunun kültürü ve biyofiziksel çevresi arasındaki ilişkiyi anlaması ve değerlendirmesi için gerekli olan beceri, tutum ve değerleri kazandırma sürecidir. Çevre eğitimi sayesinde bireyler çevrenin korunması için önemli önlemler alabilir ve kararlar alabilir (IUCN, 1970). Çevre eğitimi ayrıca bireylerin çevre sorunlarını fark etmelerine yardımcı olarak sorunlara yönelik eleştirel bir bakış açısı kazandırmayı hedeflemektedir. Çevre eğitimi sonunda bireyler sadece çevre konularını daha iyi anlamakla kalmaz çevreyi korur ve çevreyi geliştirmek için gereken tutum, bilinç ve davranışları kazanarak sorumlu bir vatandaş olarak yetiştirilebilir (Frantz ve Mayer, 2014; United States Environmental Protection Agency, 2019). Çevre eğitimi sağlıklı ve sürdürülebilir bir yaşamın ve küresel barışın teminatı olarak görülmektedir. $\mathrm{Bu}$ eğitim sayesinde farklı seviye ve karakterdeki çevresel bilgilerinin edinilmesi ve hayat boyu savunulmasıyla bireylerin yaşadığı çevre, bölge, ülke ve hatta tüm gezegen ve evren için bir sorumluluk duygusu kazanması kaçınılmazdır. Bu sayede çevresel sorumluluk bilincine sahip 
olan ve çevreyi korumayı yaşam felsefesi haline getiren dünya vatandaşları yetiştirilebilir (Atasoy, 2006).

Türkiye'de çevre eğitimi ilk olarak 1991 yılında örgün eğitim sisteminde kendine yer edinmiştir. Ardından 2000 ve 2004 yıllarında yenilenen ilköğretim programlarında da çevre konularına önem verilmiştir (Yıldırım, Bacanak ve Özsoy, 2012). Benzer şekilde 2018 öğretim programlarında da çevre eğitimine büyük bir vurgu yapılmaktadır. Özellikle ilköğretim basamağında yer alan sosyal bilgiler dersinin özel amaçları incelendiğinde öğrencilerin sürdürülebilir bir çevre anlayışına ve çevre duyarlılığına sahip olarak yaşadığı çevreyi ve dünyayı daha iyi tanıyan, insanla çevre etkileşimi anlamlandıran bireyler olarak yetişmeleri hedeflenmiştir. Benzer şekilde sosyal bilgiler öğretim programındaki insanlar, yerler ve çevreler öğrenme alanından öğrencilerin coğrafyaya odaklanarak çevrelerini ve etkileşimde bulundukları nesneleri daha yakından tanımaları, çevre sorunları konularında çeşitli beceri ve değerleri geliştirmeleri, gelecek yıllara yönelik bir bakış açısı kazanmaları amaçlanmıştır. Bu öğrenme alanı kapsamında tüm sınıf düzeylerinde öğrenim gören öğrencilerin mekanı algılama, çevre okuryazarlığ 1 , harita okuryazarlığı, değişim ve sürekliliği algılama becerilerini kazanmasını amaçlanmıştır (Milli Eğitim Bakanlığı, 2018). Benzer şekilde sosyal bilgiler öğretmenliği lisans programları incelendiğinde de çevre eğitimine veya çevre sorunlarına yönelik seçmeli alan eğitimi dersleri olan "Çevre Eğitimi, Günümüz Dünya Sorunları" derslerinin programda yer aldığ 1 görülmektedir. Derslerin içerikleri incelendiğinde ise küresel çevre sorunları olan iklim değişikliği, insanlığın geleceği, ekonomik faaliyetlerin doğal ve beşeri çevreye olan zararları, nüfus artışı, erozyon, su, toprak ve hava kirliliği gibi birçok çevre problemlerine yer verildiği görülmektedir (Yükseköğretim Kurumu, 2018). Milli Eğitim Bakanlığı Öğretmenlik Mesleği Yeterlikleri incelendiğinde de öğretmenlerin doğal çevrenin korunmasına duyarlı bireyler olması beklenmektedir (Milli Eğitim Bakanlığı, 2017).

İlgili alan yazın incelendiğinde üniversite öğrencilerinin çevre duyarlılıklarını (Arslan ve Kızıldağ, 2018; Çabuk ve Karacaoğlu, 2003), çeşitli branşlarda öğretmen adaylarının çevre sorunlarına yönelik duyarlılıklarını (Ercengiz, Keçeci Kurt ve Polat, 2014; Yıldırım ve ark., 2012), farkındalıklarını (Aydede Yalçın ve Çayc1, 2018; Köse, 2019; Özdemir ve Yapıcı, 2010; Yenice ve Alpak Tunç, 2018), tutumlarını (Gül, Çobanoğlu, Aydoğmuş ve Türk, 2018; Kahyaoğlu, Daban ve Yangın, 2008; Kahyaoğlu ve Özgen, 2011; Özgen, 2012; Polat ve Kırpık, 2013; Yılmaz, 2019) belirlemeye çalışan araştırmalara ulaşılmıştır. Ayrıca doğrudan sosyal bilgiler öğretmenlerinin veya öğretmen adaylarının çevre duyarlılıklarının (Erdoğan, 2016), çevre ile ilgili görüşlerinin (Bülbül ve Y1lmaz, 2019), çevre okuryazarlık düzeylerinin (Artun, Uzunöz ve Akbaş, 2013), çevre sorunlarına yönelik sosyal katılımlarının (Karatekin ve ark., 2014), çevre sorunlarına yönelik tutumlarının (Kayalı, 2010; Öcal, 2013) ve algılarının (Kaya, 2014) incelendiği çalışmalara da rastlanmıştır. Ancak doğrudan sosyal bilgiler lisans öğrencilerinin çevre sorunlarına yönelik farkındalıklarının incelendiği bir araştırmaya ulaşılamamıştır. Bu doğrultuda ileriki yıllarda sosyal bilgiler öğretmeni olarak görev alacak olan ve yetişecek yeni nesillerin çevreye ve çevre sorunlarına yönelik tutum, davranış ve farkındalıklarını etkileyebileceği düşünülen sosyal bilgiler öğretmen adaylarının çevre sorunlarına yönelik farkındalıklarını incelemek önemlidir.

\section{Araştırmanın Amacı}

Araştırmada sosyal bilgiler öğretmen adaylarının çevre sorunlarına yönelik farkındalıklarını incelemek amaçlanmıştır. Araştırma kapsamında oluşturulan genel amaç doğrultusunda aşağıda yer alan sorulara yanıt aranmıştır; 
1. Öğretmen adaylarının çevre sorunlarına yönelik farkındalık düzeyleri nedir?

1.1. Öğretmen adaylarının çevre sorunlarına yönelik farkındalıkları cinsiyete göre farklılaşmakta mıdır?

1.2. Öğretmen adaylarının çevre sorunlarına yönelik farkındalıkları sınıf düzeylerine göre farklılaşmakta mıdır?

1.3. Öğretmen adaylarının çevre sorunlarına yönelik farkındalıkları yaşadığı yerde çevre sorunu olma durumuna göre farklılaşmakta mıdır?

1.4. Öğretmen adaylarının çevre sorunlarına yönelik farkındalıkları çevre sorunlarına yönelik ders alma durumlarına göre farklılaşmakta mıdır?

1.5. Öğretmen adaylarının çevre sorunlarına yönelik farkındalıkları çevre sorunlarına yönelik seminer, toplantı veya kongrelere katılma durumuna göre farklılaşmakta midir?

\section{YÖNTEM}

Araştırmada, nicel araştırma yöntemlerinden tarama modeli işe koşulmuştur. Tarama modelinde, katılımcıların görüşleri, ilgi, beceri veya yetenek gibi özellikleri belirlenebilir ve bu model görece daha büyük örneklem grupları üzerinde araştırma yapılmasına olanak sağlar (Büyüköztürk, Kılıç Çakmak, Akgün, Karadeniz ve Demirel, 2015). Ayrıca araştırmaya dahil olan bireyleri, nesneleri veya olayları kendi mevcut yapısı içinde herhangi bir değiştirme veya etkileme çabası olmadan var olduğu gibi betimleme olanağı sağlar (Karasar, 2015). Bu kapsamda araştırmada öğretmen adaylarının çevre sorunlarına yönelik farkındalıklarını etkileme olasılık ve çabasından uzak bir şekilde, var olduğu gibi betimlemek amacıyla bu modelin kullanılması uygun görülmüştür.

\section{Örneklem}

Araştırmanın genel evreni, Türkiye'deki devlet üniversitelerinde eğitim alan tüm sosyal bilgiler öğretmen adaylarıdır. Çalışma evreni ise 2019-2020 eğitim-öğretim dönemi güz yarıyılında Ondokuz Mayıs Üniversitesi ve Kastamonu Üniversitesi Eğitim Fakültelerinde eğitim alan tüm sosyal bilgiler öğretmen adayları oluşturmaktadır. Araştırmada belirlenen çalışma evrenine ulaşmanın mümkün olması sebebiyle örneklem alma yoluna gidilmemiş ve ilgili bölümlerde öğrenim gören tüm öğretmen adaylarına veri toplama aracı dağıtılmıştır. Bu kapsamda 263 öğretmen adayından dönüt alınmıştır. Fakat eksik yanıtlar içeren veya samimi yanıt verilmediği tespit edilen 23 ölçek formu araştırma kapsamından çıkarılmıştır. Sonuç olarak 240 öğretmen adayından elde edilen veriler analiz işlemine tabi tutulmuştur. Araştırmanın katılımcılarına ilişkin kişisel özellikler Tablo 1'de sunulmuştur. 
Tablo 1. Katılımcıların Kişisel Özellikleri

\begin{tabular}{|c|c|c|c|c|}
\hline Özellikler & & & & $\%$ \\
\hline Cinsiyet & & & & \\
\hline & Kadın & 162 & 67.5 & \\
\hline & Erkek & 78 & 32.5 & \\
\hline Sınıf düzeyi & & & & \\
\hline 1. Sinif & & 66 & 27.5 & \\
\hline 2. $\sin i f$ & & 55 & 22.9 & \\
\hline 3. $\sin 1 f$ & & 55 & 22.9 & \\
\hline 4. sinıf & & 64 & 26.7 & \\
\hline Yaşadığı ye & e çevre sorun & & & \\
\hline & Evet & 151 & 62.9 & \\
\hline & Hayır & 38 & 15.8 & \\
\hline & Fikrim yok & 49 & 20.4 & \\
\hline & Kayıp veri & 2 & 0.8 & \\
\hline Çevre sorun & rına yönelik d & & & \\
\hline & Evet & 126 & 52.5 & \\
\hline & Hayır & 114 & 47.5 & \\
\hline Çevre sorunlarına yöneli & seminer, topla & umu & & \\
\hline & Katıldım & 103 & 42.9 & \\
\hline & Katılmadım & 137 & 57.1 & \\
\hline Toplam & & & & 100 \\
\hline
\end{tabular}

Tablo 1 incelendiğinde katılımcıların \%67,5'ini kadın, \%32,5'ini ise erkek öğretmen adaylarının oluşturduğu görülmektedir. Katılımcıların sınıf düzeyleri incelendiğinde birinci sınıf öğrencilerinin \%27,5'lik, ikinci ve üçüncü sınıf öğrencilerinin \%22,9'luk ve dördüncü sınıf öğrencilerinin \%26,7’lik bir dağılım yüzdesine sahip olduğu söylenebilir. Katılımcıların \%62,9'u yaşadığ yerde çevre sorunu olduğu düşünürken, \%15,8'i yaşadığg yerde çevre sorunu olmadığını düşünmektedir. Katılımcıların \%20,4'ü ise yaşadığı yerde çevre sorunu olup olmadığı konusunda fikri olmadığını ifade etmiştir. Bu soruya cevap vermeyenlerin oranı ise $0.8^{\prime}$ dir. Katılımcılardan \%52,5'i çevre sorunlarına yönelik ders almış, \%47,5'i ise ders almamıştır. Çevre sorunlarına yönelik seminer, toplantı veya kongrelere katılan öğretmen adaylarının oran $1 \% 42,9$ 'u iken, katılmayanların oranı ise $\% 57,1$ 'dir.

\section{Veri Toplama Yöntemleri}

Araştırma kapsamında veriler, iki ayrı kısımdan oluşan bir veri toplama aracı vasıtasıyla elde edilmiştir. Birinci kısımda öğretmen adaylarının çevre sorunlarına yönelik farkındalıklarını etkileyebileceği varsayılan cinsiyet, sınıf düzeyi, yaşadığı yerde çevre sorunu olma durumu, çevre sorunlarına yönelik ders alma ve çevre sorunlarına yönelik seminer, toplantı veya kongrelere katılma durumu değişkenlerine ait kişisel bilgiler yer almıştır.

İkinci kısımda ise asıl veri toplama aracı olan Güven ve Aydoğdu (2012) tarafindan geliştirilen “Çevre Sorunlarına Yönelik Farkındalık Ölçeği (ÇSYFÖ)” yer almıştır. Ölçeğin geliştirilmesi sürecinden önce çevre ve çevre bilimi ders kitapları ve literatürde yer alan farkındalık ölçekleri incelenmiştir. Yapılan incelemeler neticesinde ilk aşama oluşturulmuş ve öğretmen adaylarından evreni temsil edebilecek 24 kişilik bir örneklem grubu belirlenmiştir. Belirlenen örneklem grubundaki öğrencilerin çevre sorunları ile ilgili farkındalıklarını ortaya koyabilecekleri bir çalışma kağıdı verilerek kompozisyon yazmaları istenmiştir. Kompozisyon neticesinde elde edilen ifadeler için içerik analizi yapılmış ve bunun neticesinde 87 maddelik bir madde havuzu oluşturulmuştur. İkinci aşamada ise maddelerin hem olumlu hem de olumsuz ifadelerden oluşmasına özen gösterilmiş ve ölçek 3'lü likert tipinde "evet=2 puan", "fikrim yok=1 puan", "hayır=0 puan” hazırlanmıştır. Üçüncü ve dördüncü aşamalarda ölçeğin içerik 
geçerliliği, kapsam geçerliliğini ve dilbilgisi açısından uygunluğunu sınamak adına uzman görüşleri alınmış ve bu aşamada neticesinde madde sayısı 67'ye düşürülmüştür. Beşinci ve altıncı aşamalarda taslak ölçek 4. Sınıf düzeyinde 203 fen bilgisi öğretmen adayına uygulanmış ve KMO değeri .82 olarak bulunmuştur. Yedinci ve sekizinci aşamalarda ise faktör analizine ilişkin sınamalar yapılmış ve faktörler altında toplanmayan bazı maddeler atılarak altı faktör ve 44 madde ile faktör analizi sonlandırılmıştır. Ölçekteki altı faktör toplam varyansın \%63'ünü açıklamaktadır. Ölçeğin ayırt edicilik indeksinin ise .21 ile .66 arasında değiştiği bulunmuştur. Faktörlerin madde dağılımları incelendiğinde ise Bloom Taksonomisi'ne uygun olarak bilgi (8), kavrama (9), uygulama (6), analiz (8), sentez (7) ve değerlendirme (7) şeklinde dağıldığı bulunmuştur. Ölçeğin güvenilirliğini test etmek adına iç tutarlılıkla gerekli analizler yapılmış ve ölçeğin toplamında Cronbach Alfa değeri .90 olarak bulunmuştur. Alt boyutlarda Cronbach Alfa değeri ise sırasiyla $.95, .95, .91, .90, .75$ ve .71 olarak tespit edilmiştir. Ölçekten alınabilecek maksimum puan 88'iken, minimum puan ise 0'dır. Bu kapsamda ölçeğin puanlamasında 0-29 arası düşük, 30-59 arası orta ve 60-88 arası yüksek düzey farkındalık puanı olarak kabul edilmiştir.

\section{Verilerin Analizi}

Verilerin analizi aşamasında öncelikle elde edilen verilerin toplam puanları alınmıştır. Ardından verilerin normal dağılımı karşılama durumlarını belirlemek için çarpıklık ve basıklık katsayıları, Kolmogorov-Smirnov değerleri, Q-Q grafiği, kutu-çizgi grafiği, normal dağılım eğrisinin çizdirildiği histogram incelenmiştir. Yapılan incelemeler sonucunda verilerin normal dağılım özelliği göstermediği ve non-parametrik istatistiksel tekniklerin kullanılabileceği saptanmıştır. Bu doğrultuda elde edilen verilerin analizinde frekans, yüzde, standart sapma ve aritmetik ortalama gibi tanımlayıcı testler ve gruplar arası karşılaştırmalar için ilişkisiz örneklemler Mann Whitney-U ve Kruskal Wallis Testi kullanılmıştır. Araştırmada tüm istatiksel analiz işlemleri için SPSS 17 paket programı ile yapılmıştır. Testlerde gruplar arası anlamlılık düzeyi .05 olarak kabul edilmiştir.

\section{BULGULAR}

Bu bölümde öğretmen adaylarının çevre sorunlarına yönelik farkındalık ölçeğine verdikleri cevaplar neticesinde elde edilen bulgulara yer verilmiştir. Bu kapsamda öncelikle sosyal bilgiler ögretmen adaylarının çevre sorunlarına yönelik farkındalık düzeyleri aktarılmış. Ardından sosyal bilgiler öğretmen adaylarının çevre sorunlarına yönelik farkındalıklarının cinsiyet, sınıf düzeyi, yaşadığı yerde çevre sorunu olma durumu, çevre sorunlarına yönelik ders alma durumu ve çevre sorunlarına yönelik seminer, toplantı veya kongrelere katılma durumu değişkenlerine göre farklılaşıp farklılaşmadığına yönelik bulgular sunulmuştur.

\section{Sosyal Bilgiler Öğretmen Adaylarının Çevre Sorunlarına Yönelik Farkındalık Düzeyleri}

Öğretmen adaylarının ÇSYFÖ'den elde ettikleri puanlarının genel dağılımı Tablo 2'de gösterilmiştir.

Tablo 2. Öğretmen Adaylarının Çevre Sorunlarına Yönelik Farkındalık Puanlarının Genel Dağılımı

\begin{tabular}{llllll}
\hline ÇSYFÖ & N & Minimum Puan & Maksimum Puan & $\overline{\mathbf{x}}$ & Ss \\
\hline & 240 & 55 & 79 & 67.01 & .309 \\
\hline
\end{tabular}

Tablo 2 incelendiğinde, araştırmaya katılan öğretmen adaylarının ölçeğin genelinden aldığ1 minimum puanın 55, maksimum puanın ise 79 olduğu görülmektedir. Ölçeğin genelinden alınan puanların aritmetik ortalaması ise 67,01 olarak bulunmuştur. Bu bulgulara dayalı olarak 
sosyal bilgiler öğretmen adaylarının çevre sorunlarına yönelik farkındalıklarının yüksek düzeyde olduğu söylenebilir.

\section{Cinsiyet}

Sosyal bilgiler öğretmen adaylarının ÇSYFÖ’den elde ettikleri puanlar arasında cinsiyete göre anlamlı fark olup olmadığını belirlemek için yapılan Mann Whitney-U testi sonuçları Tablo 3'te gösterilmiştir.

Tablo 3. Öğretmen Adaylarının Çevre Sorunlarına Yönelik Farkındalık Puanlarının Cinsiyete Göre Mann Whitney-U Testi Sonuçları

\begin{tabular}{lllllll}
\hline ÇSYFÖ & Grup & N & Sıra Ortalaması & Sira Toplamı & U & p \\
& Kadın & 162 & 117.48 & 19031.00 & 5828.000 & .330 \\
& Erkek & 78 & 126.78 & 9889.00 & & \\
\hline
\end{tabular}

Tablo 3'teki analiz sonuçlarına göre erkek öğretmen adaylarının kadın öğretmen adaylarına göre sira ortalamalarının daha yüksek olduğu bulunmuştur. Fakat bu farklılık istatistiksel olarak anlamlı bir sonuç ortaya çıkarmamaktadır $(\mathrm{U}=5828.000 ; \mathrm{p}>.05)$. Bu bulgulardan yola çıkarak cinsiyet değişkeninin sosyal bilgiler öğretmen adaylarının çevre sorunlarına yönelik farkındalık düzeylerini etkilemediği söylenebilir.

\section{Sınıf Düzeyi}

Sosyal bilgiler öğretmen adaylarının ÇSYFÖ’den elde ettikleri puanlar arasında sınıf düzeylerine göre anlamlı fark olup olmadığını belirlemek için yapılan Kruskal Wallis testi sonuçları Tablo 4'te gösterilmiştir.

Tablo 4. Öğretmen Adaylarının Çevre Sorunlarına Yönelik Farkındalık Puanlarının Sınıf Düzeyine Göre Kruskal Wallis Testi Sonuçları

\begin{tabular}{lllllll}
\hline ÇSYFÖ & Gruplar & N & Sira Ort. & sd & $\chi^{2}$ & p \\
\hline & 1.Sinıf & 66 & 126.95 & 3 & 4.436 & .218 \\
& 2.Sinıf & 55 & 103.76 & & & \\
& 3.Sinif & 55 & 127.89 & & & \\
& 4.Sinıf & 64 & 121.88 & & & \\
\hline
\end{tabular}

Tablo 4'teki analiz sonuçların incelendiğinde 3. sınıfta öğrenim gören öğretmen adaylarının en yüksek $(127,89)$ sıra ortalamasına sahip oldukları, 2. sınıfta öğrenim gören öğretmen adaylarının ise en düşük $(103,76)$ sıra ortalamalarına sahip oldukları bulunmuştur. Fakat sınıf düzeyleri arasında ortaya çıkan bu farklılık istatistiksel olarak anlamlı değildir $(\chi 2(3)=4.436$; p>.05). Bu bulgulardan hareketle sınıf düzeyi değişkeninin sosyal bilgiler öğretmen adaylarının çevre sorunlarına yönelik farkındalık düzeylerini etkilemediği söylenebilir.

\section{Yaşadı̆̆ Yerde Çevre Sorunu Olma Durumu}

Sosyal bilgiler öğretmen adaylarının ÇSYFÖ’den elde ettikleri puanlar arasında yaşadığ 1 yerde çevre sorunu olma durumlarına göre anlamlı fark olup olmadığını belirlemek için yapılan Kruskal Wallis testi sonuçları Tablo 5'te gösterilmiştir. 
Tablo 5. Öğretmen Adaylarının Çevre Sorunlarına Yönelik Farkındalık Puanlarının Yaşadığı Yerde Çevre Sorunu Olma Durumuna Göre Kruskal Wallis Testi Sonuçları

\begin{tabular}{lllllll}
\hline ÇSYFÖ & Gruplar & N & Sira Ort. & sd & $\chi^{\mathbf{2}}$ & p \\
\hline & Evet & 151 & 120.91 & 2 & .212 & .899 \\
& Hayir & 38 & 118.71 & & & \\
& Fikrim yok & 49 & 115.78 & & & \\
\hline
\end{tabular}

Tablo 5'teki analiz sonuçları incelendiğinde, yaşadığı yerde çevre sorunu olan öğretmen adaylarının (120.91), yaşadığ 1 yerde çevre sorunu olmayan (118.71) ve yaşadığ1 yerde çevre sorunu olup olmadığı konusunda fikri olmayan (115.71) öğretmen adaylarına göre daha yüksek sıra ortalamalarına sahip olduğu bulunmuştur. Fakat yaşadığ 1 yerde çevre sorunu olma durumlarına göre elde edilen sıra ortalamaları arasında istatistiksel olarak anlamlı bir farklılığa rastlanmamıştır $(\chi 2(3)=.212 ; \mathrm{p}>.05)$. Bu bulgulardan hareketle sosyal bilgiler öğretmen adaylarının çevre sorunlarına yönelik farkındalıklarının yaşadığı yerde çevre sorunu olma durumlarına göre değişmediği söylenebilir.

\section{Çevre Sorunlarına Yönelik Ders Alma Durumu}

Sosyal bilgiler öğretmen adaylarının ÇSYFÖ'den elde ettikleri puanlar arasında çevre sorunlarına yönelik ders alma durumuna göre anlamlı fark olup olmadığını belirlemek için yapılan Mann Whitney-U testi sonuçları Tablo 6' da gösterilmiştir.

Tablo 6. Öğretmen Adaylarının Çevre Sorunlarına Yönelik Farkındalık Puanlarının Çevre Sorunlarına Yönelik Ders Alma Durumlarına Göre Mann Whitney-U Testi Sonuçları

\begin{tabular}{lllllll}
\hline ÇSYFÖ & Grup & $\mathbf{N}$ & Sira Ortalaması & Sira Toplamı & U & p \\
\hline & Evet & 126 & 117.54 & 14810.00 & 6809.000 & .486 \\
& Hayır & 114 & 123.77 & 14110.00 & & \\
\hline
\end{tabular}

Tablo 6'daki analiz sonuçları incelendiğinde, çevre sorunlarına yönelik ders almayan (123.77) öğretmen adaylarının ders alan (117.54) öğretmen adaylarına göre daha yüksek sıra ortalamalarına sahip oldukları bulunmuştur. Ancak çevre sorunlarına yönelik ders alma durumlarına göre elde edilen sıra ortalamaları arasında istatistiksel olarak anlamlı bir farklılığa ulaşılamamıştır $(\mathrm{U}=6809.000 ; \mathrm{p}>.05)$. Bu bulgulardan yola çıkarak sosyal bilgiler öğretmen adaylarının çevre sorunlarına yönelik ders alma durumlarının çevre sorunlarına yönelik farkındalıklarını etkilemediği söylenebilir.

\section{Çevre Sorunlarına Yönelik Seminer, Toplantı veya Kongrelere Katılma Durumu}

Sosyal bilgiler öğretmen adaylarının ÇSYFÖ'den elde ettikleri puanlar arasında çevre sorunlarına yönelik seminer, toplantı veya kongrelere katılma durumuna göre anlamlı fark olup olmadığını belirlemek için yapılan Mann Whitney-U testi sonuçları Tablo 7'de gösterilmiştir.

Tablo 7. Öğretmen Adaylarının Çevre Sorunlarına Yönelik Farkındalık Puanlarının Çevre Sorunlarına Yönelik Seminer, Toplantı veya Kongrelere Katılma Durumlarına Göre Mann Whitney-U Testi Sonuçları

\begin{tabular}{lllllll}
\hline ÇSYF̈̈ & Grup & N & Sıra Ortalaması & Sıra Toplamı & U & p \\
\hline & Katıldım & 103 & 131.71 & 13566.00 & 5901.000 & .030 \\
& Katılmadım & 137 & 112.07 & 15354.00 & & \\
\hline
\end{tabular}

Tablo 7'deki analiz sonuçları incelendiğinde, çevre sorunlarına yönelik seminer, toplantı veya kongrelere katılan (131.71) öğretmen adaylarının katılmayan (112.07) öğretmen adaylarına göre daha yüksek sıra ortalamalarına sahip olduğu görülmektedir. Yapılan Mann Whitney-U 
testi sonucunda bu farklılı̆̆ın istatistiksel olarak anlamlı olduğu bulunmuştur ( $U=5901.000$; $\mathrm{p}<.05)$. Bu bulgulara göre sosyal bilgiler öğretmen adaylarının çevre sorunlarına yönelik seminer, toplantı veya kongrelere katılmalarının çevre sorunlarına yönelik farkındalıklarını etkilediği söylenebilir.

\section{TARTIŞMA, SONUÇ ve ÖNERÍLER}

$\mathrm{Bu}$ araştırmada sosyal bilgiler öğretmen adaylarının çevre sorunlarına yönelik farkındalıklarını incelemek amaçlanmıştır. Ayrıca araştırmada sosyal bilgiler öğretmen adaylarının çevre sorunlarına yönelik farkındalıklarının cinsiyet, sınıf düzeyi, yaşadığı yerde çevre sorunu olma, çevre sorunlarına yönelik ders alma ve çevre sorunlarına yönelik seminer, toplantı veya kongrelere katılma durumlarına göre değişip değişmediği incelenmiştir. Araştırmadan elde edilen bulgulara göre sosyal bilgiler öğretmen adaylarının çevre sorunlarına yönelik yüksek düzeyde farkındalığa sahip olduğu sonucuna ulaşılmıştır. İlgili alan yazın incelendiğinde araştırmanın bu sonucuyla benzerlik gösteren araştırmalara ulaşılmıştır. Örneğin Öcal (2013) tarafından yapılan araştırmada öğretmen adaylarının çevreye yönelik olumlu tutuma sahip oldukları belirlenmiştir. Benzer şekilde Kaya'nın (2014) metaforlar aracılığıyla sosyal bilgiler öğretmen adaylarının çevre sorunlarına yönelik algıları belirlediği araştırmada, öğretmen adaylarının ürettikleri metaforlardan çevre sorunlarının doğal dengeyi aşacak oranda arttığını anlamaları ve bu artışın insan yaşamını olumsuz bir biçimde etkilemesini düşünmeleri öğretmen adaylarının yüksek düzeyde farkındalık ve tutuma sahip olduğu şeklinde yorumlanmıştır. Bülbül ve Yılmaz'ın (2019) araştırmasında da öğretmen adaylarının kendilerini çevresel vatandaş olarak algıladıkları bulunmuştur. Çeşitli branşlarda öğretmen adaylarının çevre sorunlarına yönelik farkındalıklarını inceleyen bazı araştırmalarda da (Köse, 2019; Özdemir ve Yapıc1, 2010; Yenice ve Alpak Tunç, 2018) öğretmen adaylarının yüksek düzeyde veya olumlu düzeyde çevre sorunlarına yönelik farkındalıklara sahip olduğu belirlenmiştir. Bu sonuçların aksine ise alan yazında çeşitli branşlarda öğretmen adaylarının çevre sorunlarına yönelik tutumlarının ve çevre sorunlarına karşı duyarlılıklarının orta düzeyde (Kahyaoğlu ve Özgen, 2011; Yıldırım ve ark., 2012) veya düşük düzeyde bulunduğu (Çabuk ve Karacaoğlu, 2003; Karatekin ve ark., 2004) araştırmalar da bulunmaktadır. Örneğin Çabuk ve Karacaoğlu (2003) tarafından yapılan araştırmada, öğrencilerin çoğunun çevre sorunlarını azaltma konusunda ortak düşüncelere sahip oldukları fakat çevre sorunlarını azaltmak için gerekli uygulamaları yapma noktasında yeterli duyarlılığı göstermedikleri bulunmuştur. Karatekin ve arkadaşlarının (2014) yaptığı çalışmada da öğrencilerin çevre sorunlarına yönelik kaygılarının yüksek olmasına rağmen kaygılarını giderecek davranışlar içerisine girmedikleri ve çevre sorunlarını çözme noktasında sosyal katılım göstermedikleri bulunmuştur. Ayrıca bu araştırmada öğretmen adaylarının çevre sorunlarına karşı farkındalık, ilgi, bilgi ve bilişsel beceri düzeylerinin çok düşük olduğu tespit edilmiştir.

Araştırmada erkek sosyal bilgiler öğretmen adaylarının kadın öğretmen adaylarına göre daha yüksek düzeyde farkındalık puanlarına sahip olduğu fakat bu farklılığın istatistiksel olarak anlamlı bir sonuç ortaya çıkarmadığı tespit edilmiştir. İlgili alan yazında çeşitli branşlarda öğretmen adaylarının çevre sorunlarına karşı duyarlılıklarının (Arslan ve Kızıldağ, 2018; Ercengiz ve ark., 2014; Yıldırım ve ark., 2012), farkındalıkların (Köse, 2019), tutumlarının (Kahyaoğlu ve ark., 2008; Polat ve Kırpık, 2013) ve çevre okuryazarlık düzeylerinin (Artun ve ark., 2013) incelendiği araştırmalarda da cinsiyet değişkenine göre anlamlı farklılıklara rastlanmamıştır. $\mathrm{Bu}$ sonuçlar araştırmanın sonuçlarını destekler niteliktedir. $\mathrm{Bu}$ sonuçların aksine ise cinsiyet değişkeninin çevre sorunlarına yönelik farkındalıkları (Aydede Yalçın ve Çaycı, 2018), tutumları (Kahyaoğlu ve Özgen, 2011; Kayalı, 2010; Öcal, 2013; Özgen, 2012;) 
ve duyarlılıkları (Çabuk ve Karacaoğlu, 2003) kadın öğretmen adayları lehine etkilediği kimi araştırmalara da ulaşılmıştır. Örneğin Aydede Yalçın ve Çaycı'nın (2018) öğretmen adaylarının çevresel farkındalıklarını incelediği araştırmada kadın öğretmen adayları lehine anlamlı farklılık bulunmuştur. Benzer şekilde Kayalı (2010) tarafından yapılan araştırmada da kadın öğrenciler lehine anlamlı farklılıklara rastlanmıştır. Son olarak Öcal'ın (2013) yaptığı araştırmada kadın öğretmen adaylarının çevreye yönelik tutumlarının daha yüksek düzeyde olduğu ve bu sonucun istatistiksel olarak anlamlı olduğu bulunmuştur.

Araştırmada 3. sınıf düzeyinde öğrenim gören öğretmen adaylarının en yüksek farkındalık puanına sahip olduğu, 2. sınıf düzeyindeki öğretmen adaylarının ise en düşük farkındalık puanına sahip olduğu belirlenmiştir. Fakat yapılan analizler neticesinde sınıf düzeyi değişkeninin sosyal bilgiler öğretmen adaylarının çevre sorunlarına yönelik farkındalıklarını istatistiksel olarak anlamlı bir biçimde etkilemediği tespit edilmiştir. İlgili literatürde araştırmanın bu sonuçları ile benzerlik gösteren kimi araştırmalara ulaşılmıştır. Örneğin öğretmen adaylarının sınıf değişkenine göre çevre sorunlarına yönelik duyarlılık puanlarında (Ercengiz ve arkadaşları, 2014) ve çevre sorunlarına yönelik tutum puanlarında(Güven, Yurdatapan, Benzer ve Şahin, 2010; Özgen, 2012) anlamlı bir farklılığın olmadığı araştırmalar bulunmaktadır. Bu sonuçların aksine ise Çabuk ve Karacaoğlu (2003) tarafından eğitim bilimleri fakültesi öğrencilerinin çevre duyarlılığına ilişkin görüşlerini incelendiği çalışmada 4. sınıf öğretmen adaylarının diğer öğretmen adaylarına göre daha yüksek düzeyde çevre duyarlılığına sahip olduğu ve istatistiksel olarak anlamlı bir farklılık olduğu bulunmuştur. Benzer şekilde Yıldırım ve arkadaşları (2012) tarafından çeşitli branşlarda öğretmen adaylarının çevre sorunlarına karşı duyarlılıklarının incelediği araştırmada 4. sınıf öğretmen adayları ile 2. sinıf öğretmen adayları arasında 4. sınıf öğretmen adayları lehine anlamlı farklılıkların olduğun tespit edilmiştir.

Araştırmada yaşadığı yerde çevre sorunu olan sosyal bilgiler öğretmen adaylarının diğerlerine göre daha yüksek farkındalık puanlarına sahip olduğu fakat bu farklılığın istatistiksel olarak anlamlı bir sonuç ortaya çıkarmadığı tespit edilmiştir. Bu sonuçlardan yola çıkarak yaşadığı yerde çevre sorunu olma durumu değişkeninin sosyal bilgiler öğretmen adaylarının çevre sorunlarına yönelik farkındalıklarını etkilemediği söylenebilir. İlgili alan yazında araştırmanın bu bulgusunun aksine sosyal bilgiler öğretmenlerinin çevre duyarlılıklarının üzerinde etkili olan etmenlerden birinin yaşamış oldukları çevre sorunları olduğu tespit edilmiştir (Erdoğan, 2016). $\mathrm{Bu}$ sonuçların farklılık göstermesinin Erdoğan (2016) tarafından yapılan çalışmanın nitel araştırma desenleri ile işe koşulmasının ve araştırmaya dahil edilen katılımcı grubunun en az 5 yıllık deneyime sahip olan öğretmenlerden oluşmasının neden olduğu düşünülmektedir.

Araştırmada çevre sorunlarına yönelik ders almayan öğretmen adaylarının ders alan öğretmen adaylarına göre daha yüksek farkındalık puanlarına sahip olduğu belirlenmiştir. Fakat yapılan analizler neticesinde çevre sorunlarına yönelik ders alma değişkeninin sosyal bilgiler öğretmen adaylarının çevre sorunlarına yönelik farkındalıklarını istatistiksel olarak anlamlı bir şekilde etkilemediği sonucuna ulaşılmıştır. İlgili literatürde araştırmanın bu sonuçlarına benzer olarak Aydede Yalçın ve Çaycı (2018) tarafından öğretmen adaylarının çevresel farkındalıklarının incelendiği araştırmada öğretmen adaylarının çevre dersi alma durumlarının çevresel farkındalıklarını etkilemediği bulunmuştur. Kahyaoğlu ve arkadaşları (2008) tarafından yapılan araştırma da tutum puanlarının öğretmen adaylarının üniversitede çevre dersini alıp almama durumlarına göre değişmediği ve istatistiksel olarak anlamlı bir sonuç ortaya koymadığı tespit edilmiştir. Son olarak Çabuk ve Karacaoğlu'nun (2003) çalışmasında ise öğretmen adaylarının öğrenim gördükleri üniversitede hava, su, toprak ve ekolojik denge konularında 
farkındalıklarını artırabilecek bir eğitimin olmadığını düşündükleri tespit edilmiştir. $\mathrm{Bu}$ sonuçların aksine ise Kayalı (2010) tarafından sosyal bilgiler, Türkçe ve sınıf öğretmenliği ögretmen adaylarının çevre sorunlarına yönelik tutum puanlarında çevre sorunları ile ilgili ders alan sosyal bilgiler ve sınıf öğretmenliği öğretmen adayları lehine anlamlı bir farklılığa rastlanmıştır. Yine Erdoğan'ın (2016) sosyal bilgiler öğretmenlerinin çevre duyarlılıklarını nitel araştırma yöntemleri ile incelediği araştırmada çevre duyarlılı̆̆ 1 ile çevre eğitimine ilişkin algılarında bir paralellik bulunmuş ve çevre eğitiminin çok önemli olduğu sonucuna ulaşılmıştır. Son olarak Gül, Aydoğmuş, Çobanoğlu ve Türk (2018b) tarafından üniversite öğrencilerinin çevre bilinçlerinin incelendiği araştırmada çevre eğitimi dersini alan öğrencilerin çevre bilinç düzeylerinin ortalamanın üstünde olduğu ve çevre yönelik bilinç düzeylerini olumlu yönde etkilediği sonucuna ulaşılmıştır. İlgili literatürdeki araştırma sonuçlarının farklılık göstermesinin temel sebebinin araştırmaların yapıldığı üniversitelerde çevre eğitimi dersini veren öğretim üyelerinin veya öğrenci yeterliklerinin farklı olmasının, kullanılan araştırma yöntemi ve veri toplama araçlarının kapsamlarının farklılık göstermesi olduğunu düşünülmektedir.

Sosyal bilgiler öğretmen adaylarının çevre sorunlarına yönelik seminer, toplantı veya kongrelere katılma durumlarına göre çevre sorunlarına yönelik farkındalıkları incelendiğinde, seminer, toplantı veya kongrelere katılan öğretmen adaylarının katılmayanlara göre daha yüksek düzeyde çevre sorunlarına yönelik farkındalık puan ortalamalarına sahip olduğu sonucuna ulaşılmıştır. Yapılan analizler neticesinde bu farklılığın istatistiksel olarak anlamlı sonuçlar ortaya koyduğu tespit edilmiştir. Bu sonuçlardan yola çıkarak sosyal bilgiler öğretmen adaylarının çevre sorunlarına yönelik seminer, toplantı ve kongrelere katılmasının çevre sorunlarına yönelik farkındalıklarını olumlu yönde arttırdığı söylenebilir. Arslan ve Kızıldağ (2018) tarafından öğretmen adaylarının çevre duyarlılıklarının incelendiği araştırmada ise öğrencilerin geçmiş deneyimlerinin ders almaları, katıldıkları bir etkinlik, okudukları kitaplar, izledikleri filmlere göre çevre bilinçlerinde de anlamlı bir farklılığa rastlanmamıştır. Bu iki araştırmanın sonuçların farklılık göstermesinin nedeninin ise Arslan ve Kızıldağ'ın (2018) çalışmasında bu boyut kapsamında yer alan ders alma, etkinliklere katılma, okudukları kitaplar vb. gibi birçok faktörü geçmiş deneyimler olarak bütünleştirilmesinin neden olduğu düşünülmektedir.

Araştırma sonuçları genel olarak incelendiğinde öğretmen adaylarının cinsiyet, sınıf düzeyi, yaşadığı yerde çevre sorunu olma durumu, çevre sorunlarına yönelik ders alma durumu değişkenlerine göre çevre sorunlarına yönelik farkındalıklarında bir farklılık olmadığı tespit edilmiştir. Bu sonuçlardan yola çıkarak bazı yorumlar ve öneriler yapılabilir. Sosyal bilgiler öğretmenliği lisans programlarında çevre eğitimi veya çevre sorunlarına yönelik birçok ders yer almasına rağmen öğretmen adaylarının sınıf düzeyleri arttıkça çevre sorunlarına yönelik farkındalıklarının artmaması araştırmanın ilginç sonuçlarından biridir. Ayrıca çevre sorunlarına yönelik ders alma değişkeninde ders alan öğretmen adaylarının ders almayan öğretmen adaylarına göre herhangi bir farklılığa sahip olmaması da bir noktada sınıf düzeyi değişkeninin sonuçlarını doğrulamaktadır. Bu doğrultuda ileriki yıllarda öğrencilerine çevre konularında bakış açısı kazandırması olası görülen öğretmen adaylarının çevre sorunlarına karşı farkındalık düzeylerinin artırılması için lisans ders içeriklerinin gözden geçirilmesi önerilebilir. Araştırmanın şaşırtıcı sonuçlarından biri de yaşadığı yerde çevre sorunu olan öğretmen adaylarının çevre sorunu olmayan öğretmen adaylarına göre bir farkındalığa sahip olmamasıdır. Buradan hareketle öğretmen adaylarının yaşadıkları yerde bir çevre sorunu olsa dahi buna kayıtsız kaldığı veya bu konu hakkında bir farkındalığa tam anlamıyla sahip olmadığ1 söylenebilir. Bu doğrultuda lisans düzeyinde çevre sorunları veya çevre eğitimi ile ilgili verilen 
derslerde ülke genelindeki çevre sorunları öğrencilere daha kapsamlı bir şekilde aktarılabilir. Öte yandan araştırma sonuçlarından yola çıkarak öğretmen adaylarının çevre sorunlarına yönelik seminer, toplantı veya kongrelere katılmalarının farkındalıklarını etkilediği tespit edilmiştir. Bu kapsamda üniversiteler, belediyeler veya sivil toplum örgütleri tarafından çevre sorunlarına yönelik seminer, toplantı veya kongrelerinin düzenlenme sıklığı artırılabilir ve öğretmen adaylarının bu yerlere katılımı için destekler sağlanabilir. Son olarak gelecek araştırmalarda öğretmen adaylarının çevre sorunlarına yönelik farkındalıklarını derinlemesine inceleyen nitel araştırmaların yapılması önerilebilir. Ayrıca ilgili alan yazında karma araştırma yöntemleri ile öğretmenlerin veya öğretmen adaylarının çevre sorunlarına yönelik farkındalıklarını inceleyen bir araştırmaya rastlanmamıştır. Bu bağlamda geliştirilecek ders içerikleri ile karma yöntem ile işe koşulan araştırmalar tasarlanabilir.

\section{KAYNAKÇA}

Arslan, K. ve Kızıldağ, H. A. (2018). Üniversite öğrencilerinin çevre duyarlılıklarının çeşitli değişkenler açısından incelenmesi: Buca Eğitim Fakültesi örneği. Akademik Sosyal Araştırmalar Dergisi, 6(84), 175-192. http://dx.doi.org/10.16992/ASOS.14455

Artun, H., Uzunöz, A. ve Akbaş, Y. (2013). Sosyal bilgiler öğretmen adaylarının çevre okur-yazarlık düzeylerine etki eden faktörlerin değerlendirilmesi. Pamukkale Üniversitesi Eğitim Fakültesi Dergisi, 34, 1-14. Erişim adresi: http://pauegitimdergi.pau.edu.tr/Makaleler/1550975017_1.pdf

Atasoy, E. (2006). Çevre için ĕgitim: Çocuk doğa etkileşimi. Bursa: Ezgi Kitabevi.

Aydede Yalçın, M. N. ve Çaycı, B. (2018). Öğretmen adaylarının çevresel farkındalıklarının sosyo-demografik özellikleri açısından incelenmesi. Trakya Ĕ̆itim Dergisi, 8(3), 578-590. Doi: 10.24315/ trkefd.316242

Balkan Kıyıcı, F. (2009). Çevre eğitimi. Sevinç, V. (Ed.), Eğitim fakülteleri için genel çevre bilimi içinde (s. 173183). Ankara: Maya Akedemi.

Bülbül, Y. ve Yılmaz, A. (2019). Sosyal bilgiler öğretmen adaylarının çevre, çevre eğitim ve çevresel vatandaşlık kavramlarına ilişkin görüşleri. Uluslararası Sosyal Bilimler Ĕgitimi Dergisi, 5(2), 165-183. Erişim adresi: https://dergipark.org.tr/tr/download/article-file/868832

Büyüköztürk, Ş., Kılıç Çakmak, E., Akgün, Ö. E., Karadeniz, Ş. ve Demirel, F. (2015). Bilimsel araştırma yöntemleri (19. Baskı). Ankara: Pegem Akademi Yayıncılık.

Çabuk, B. ve Karacaoğlu, Ö. C. (2003). Üniversite öğrencilerinin çevre duyarlılıklarının incelenmesi. Ankara Üniversitesi Eğitim Bilimleri Fakültesi Dergisi, 36(1-2), 189-198. Erişim adresi: http://dergiler.ankara.edu.tr/dergiler/40/141/1005.pdf

Çevre ve Şehircilik Bakanlığı. (2018). Projeler. 14 Ekim 2019 tarihinde https://csb.gov.tr/uygulamalar, adresinden edinilmiştir.

Ercengiz, M., Keçeci Kurt, S. ve Polat, S. (2014). Öğretmen adaylarının çevre sorunlarına yönelik duyarlılıklarının incelenmesi (Ağrı ili örneği). Ekev Akademi Dergisi, 18 (59), 119-132. Erişim adresi: http://www.ekevakademi.org/Makaleler/912891929 08\%20Mustafa\%20ERCENGIZSoncul\%20KECECI\%20KURT\%20-\%20Suat\%20POLAT\%20(1).pdf

Erdoğan, M. (2016). Sosyal bilgiler öğretmenlerinin çevre duyarlılıklarının değgerlendirilmesi: Fethiye örneği. (Yüksek lisans tezi, Muğla Sitkı Koçman Üniversitesi, Eğitim Bilimleri Enstitüsü, Muğla). https://tez.yok.gov.tr/UlusalTezMerkezi/tezSorguSonucYeni.jsp adresinden edinilmiştir.

Frantz, C. M. \& Mayer, F. S. (2014). The importance of connection to nature in assessing environmental education programs. Studies in Educational Evaluation, 41, 85-89. https://doi.org/10.1016/j.stueduc.2013.10.001

Gül, İ., Çobanoğlu, İ. H., Aydoğmuş, M. ve Türk, H. (2018). Sınıf öğretmenlerinin çevreye yönelik tutumlarının incelenmesi: Samsun ili örneği. Ondokuz Mayıs Üniversitesi Eğitim Fakültesi Dergisi, 37(2), 139-157. DOI: $10.7822 /$ omuefd. 427161 
Gül, S., Aydoğmuş, M., Çobanoğlu, İ. H. ve Türk, H. (2018b). Üniversite öğrencilerinin çevre bilinçlerinin incelenmesi: Ondokuz Mayıs Üniversitesi örneği. Gazi Ĕ̆itim Bilimleri Dergisi, 4(3), 13-28. Erişim adresi: https://dergipark.org.tr/tr/download/article-file/584049

Güven, E. ve Aydoğdu, M. (2012). Çevre sorunlarına yönelik farkındalık ölçeğinin geliştirilmesi ve öğretmen adaylarının farkındalık düzeylerinin belirlenmesi. Öğretmen Ĕgitimi ve Ĕgitimcileri Dergisi, 1(2), 185 202. Erişim adresi: http://www.jtee.org/document/issue2/2mak.pdf

Güven, İ., Yurdatapan, M., Benzer, E. ve Şahin, F. (2013). Fen bilgisi öğretmen adaylarının çevre sorunlarına yönelik tutumları ile sağlıklı yaşama yönelik tutumlarının değerlendirilmesi. Kastamonu Eğitim Dergisi, 21(4), 1431-1448. Erişim adresi: https://dergipark.org.tr/tr/download/article-file/209968

İnternational Union for Conservation of Nature and Natural Resources (1970). Final Report: İnternational working meeting on environmental education in the school curriculum. Retrieved October 15, 2019, from https://portals.iucn.org/library/sites/library/files/documents/Rep-1970-001.pdf

Kahyaoğlu, M. ve Özgen, N. (2011). Öğretmen adaylarının çevre sorunlarına yönelik tutumlarının çeşitli değişkenler açısından incelenmesi. Kurumsal Eğitim Bilim Dergisi, 5(2), 171-185. Erişim adresi: https://dergipark.org.tr/tr/download/article-file/304187

Kahyoğlu, M., Daban, Ş. ve Yangın, S. (2008). İlköğretim öğretmen adaylarının çevreye yönelik tutumları. Dicle Üniversitesi Ziya Gökalp Eğitim Fakültesi Dergisi, 11, 42-52. Erişim adresi: https://dergipark.org.tr/en/download/article-file/787154

Karasar, N. (2015). Bilimsel araştırma yöntemleri (28. Baskı). Ankara: Nobel Akademi Yayıncılık.

Karatekin, K., Kuş, Z. ve Merey, Z. (2014). Sosyal bilgiler öğretmen adaylarının çevre sorunlarının çözümünde sosyal katılımları. Ilkögretim Online, 13(2), 345-361. Erişim adresi: https://www.researchgate.net/publication/312631430_Sosyal_Bilgiler_Ogretmen_Adaylarinin_Cevre_S orunlarinin_Cozumunde_Sosyal_Katilimlari

Kaya, M. F. (2014). Sosyal bilgiler öğretmen adaylarının çevre sorunlarına ilişkin algıları: Metafor analizi örneği. Turkish Studies, 9(2), 917-931. http://www.turkishstudies.net/Makaleler/2020509839_52KayaMehmetFatih-sos-917-931.pdf?

Kayalı, H. (2010). Sosyal bilgiler, Türkçe ve sınıf öğretmenliği öğretmen adaylarının çevre sorunlarına yönelik tutumları. Marmara Coğrafya Dergisi, 21, 258-268. Erişim adresi: http://dspace.marmara.edu.tr/bitstream/handle/11424/2582/630-1219-1 $\underline{\text { SM.pdf? sequence }=1 \& \text { isAllowed }=y}$

Köse, N. (2019). Beden ĕgitimi ve spor öğretmeni adaylarının çevre sorunlarına ilişkin farkındalık ve tutum düzeylerinin incelenmesi. (Yüksek lisans tezi, Niğde Ömer Halis Demir Üniversitesi, Sosyal Bilimler Enstitüsü, Niğde). $\quad$ https://tez.yok.gov.tr/UlusalTezMerkezi/tezSorguSonucYeni.jsp adresinden edinilmiştir.

Köylü, M. (2011). Çevre sorunlarından çevre eğitimine. Eskiyeni, 21, 56-64. Erişim adresi: https://dergipark.org.tr/tr/download/article-file/482323

Millî Eğitim Bakanlığı. (2017). Öğretmen mesleği genel yeterlikleri. 14 Ekim 2019 tarihinde https://oygm.meb.gov.tr/meb_iys_dosyalar/2017_12/11115355_YYRETMENLYK_MESLEYY_GENEL_ YETERLYKLERY.pdf, adresinden edinilmiştir.

Millî Eğitim Bakanlığı. (2018). Sosyal Bilgiler Dersi Öğretim Programı (İlkokul ve Ortaokul 4, 5, 6 ve 7. sınıflar). 14 Ekim 2019 tarihinde, http://mufredat.meb.gov.tr/Dosyalar/201812103847686SOSYAL\%20B\%C4\%BOLG\%C4\%BOLER\%20\%C3\%96\%C4\%9ERET\%C4\%BOM\%20PROGRAMI\%20 .pdf, adresinden edinilmiştir.

Öcal, T. (2013). Sosyal bilgiler öğretmen adaylarının çevre sorunlarına yönelik tutumlarının belirlenmesi. Marmara Coğrafya Dergisi, 27, 333-352. Erişim http://dspace.marmara.edu.tr/bitstream/handle/11424/2702/754-1467-1SM.pdf?sequence $=1 \&$ isAllowed $=y$

Özbebek Tunç, A., Akdemir Ömür, G. ve Düren, A. Z. (2012). Çevresel farkındalık. İstanbul Üniversitesi Siyasi Bilgiler Fakültesi Dergisi, 47, 227-246. Erişim adresi: https://dergipark.org.tr/tr/download/articlefile/5698 
Özdemir, A. ve Yapıcı, E. (2010). Öğretmen adaylarının çevre sorunlarına yönelik farkındalık ve ilgi düzeylerinin karşılaştırılması. Anadolu Doğa Bilimleri Dergisi, 1(1), 48-56. Erişim adresi: https://docplayer.biz.tr/9281541-Ogretmen-adaylarinin-cevre-sorunlarina-yonelik-farkindalik-ve-ilgiduzeylerinin-karsilastirilmasi.html

Özdemir, O. (2007). Yeni bir çevre eğitimi perspektifi: “Sürdürülebilir gelişme amaçlı eğitim”. Eğitim ve Bilim, 32(145), 23-39. Erişim adresi: http://egitimvebilim.ted.org.tr/index.php/EB/article/view/813/166

Özey, R. (2001). Çevre sorunları. İstanbul: Aktif Yayınevi.

Özey, R. (2001b). Günümüz dünya sorunları. İstanbul: Aktif Yayınevi.

Özgen, N. (2012). Öğretmen adaylarının çevre sorunlarına yönelik tutumları: Türkiye örneği. Kastamonu Ĕ̆itim Dergisi, 20(2), 403-422. Erişim adresi: https://dergipark.org.tr/en/download/article-file/806951

Polat, S. ve Kırpık, C. (2013). Öğretmen adaylarının çevre sorunlarına yönelik tutumları. Bartın Üniversitesi Eğitim Fakültesi Dergisi, 2(1), 205-227. Erişim adresi: https://dergipark.org.tr/tr/download/article$\underline{\text { file/43571 }}$

Türkiye Büyük Millet Meclisi. (1982). Türkiye Cumhuriyeti Anayasası. 16 Ekim 2019 tarihinde, https://www.mevzuat.gov.tr/MevzuatMetin/1.5.2709.pdf adresinden edinilmiștir.

United States Environmental Protection Agency. (2019). What is environmental education? Retrieved October 17, 2019, from https://www.epa.gov/education/what-environmental-education

Türk Mühendis ve Mimar Odaları Birliği Çevre Mühendisleri Odası (2018). Hava Kirliliği Raporu 2018. Erişim adresi: http://cmo.org.tr/resimler/ekler/9d62b3a2bb620a4_ek.pdf

Yenice, N. ve Alpak Tunç, G. (2018). Fen bilgisi öğretmen adaylarının çevre sorunlarına yönelik farkındalıkları ile yenilenebilir enerji kaynaklarına yönelik tutumlarının incelenmesi. Uludă̆ Üniversitesi Eğitim Fakültesi Dergisi, 31(1), 207-222. Erişim adresi: https://dergipark.org.tr/tr/download/article-file/517814

Yıldırım, C., Bacanak, A. ve Özsoy, S. (2012). Öğretmen adaylarının çevre sorunlarına karşı duyarlılıkları. Kastamonu Eğitim Dergisi, 20(1), 121-134. Erişim adresi: https://dergipark.org.tr/en/pub/kefdergi/issue/48696/619513

Yıldız, K., Sipahioğlu, Ş. ve Yılmaz, M. (2005). Çevre bilimi ve eğitimi. Ankara: Gündüz Eğitim ve Yayıncılık.

Yılmaz, N. (2019). Fen bilgisi, sosyal bilgiler, Türkçe eğitimi öğretmen adaylarının çevre sorunlarına ve çevreye dair davranış ve tutumlarının çok boyutlu incelenmesi. (Yüksek lisans tezi, Gaziantep Üniversitesi, Eğitim Bilimleri Enstitüsü, Gaziantep). https://tez.yok.gov.tr/UlusalTezMerkezi/tezSorguSonucYeni.jsp adresinden edinilmiştir.

Yükseköğretim Kurumu. (2018). Sosyal bilgiler öğretmenliği lisans programı. 18 Ekim 2019 tarihinde, https://www.yok.gov.tr/Documents/Kurumsal/egitim ogretim dairesi/Yeni-Ogretmen-Yetistirme-LisansProgramlari/Sosyal Bilgileri_Ogretmenligi_Lisans_Programi09042019.pdf, adresinden edinilmiștir. 


\title{
EXTENDED ABSTRACT
}

\author{
An Analysis About Social Studies Prospective Teachers' Awereness Levels on \\ Environmental Problems
}

\section{Introduction}

The environment is of paramount importance for living things. They live in it, establish a connection with it, and affect and are affected by it in numerous ways. Problems that harm living things and disrupt the natural balance are referred to as environmental issues. However, human and economic activities especially in the last century have been damaging the environment and disrupting its balance to create new artificial environments, making environmental issues more multidimensional and complicated. Countries dealing with environmental issues have found themselves in a tight corner. In the 1970s, politicians, educators, and scientists started to focus on finding solutions to environmental issues and took several steps such as imposing fines, setting up environmental protection organizations, taking protective and deterrent measures, and discovering alternative energy sources. However, none of those measures is as effective in solving environmental issues as raising people's environmental awareness because unless we do it, we cannot create a habitable environment. Only if we raise people's environmental awareness, we can adopt policies and measures to resolve those issues. Raising young people's environmental awareness is of key importance for a sustainable future. The objective of the primary school social studies course in Turkey is to transform students into individuals who know about their immediate surroundings and the general geographical characteristics of the world, recognize the interaction between human and environment, and the limitations of the environment and natural resources, and have environmental awareness and a clear understanding of a sustainable environment. The course informs students about environmental issues and raises their environmental awareness and helps them develop skills. However, this can only be achieved by teachers who themselves have environmental awareness.

The aim of this study was to determine preservice social studies teachers' awareness of environmental issues. To that end, the study sought answers to the following questions:

1. How aware are social studies preservice teachers of environmental issues?

1.1. Does social studies preservice teachers' awareness of environmental issues differ by gender?

1.2. Does social studies preservice teachers' awareness of environmental issues differ by grade level?

1.3. Does social studies preservice teachers' awareness of environmental issues differ by experiencing environmental issues where they live?

1.4. Does social studies preservice teachers' awareness of environmental issues differ by having taken courses on environmental issues?

1.5. Does social studies preservice teachers' awareness of environmental issues differ by having attended seminars, meetings or conferences on environmental issues?

\section{Method}

Screening model, which is a quantitative research method, was used. The study sample consisted of 240 social studies students of the Education Faculties of Ondokuz Mayis 
University and Kastamonu University in the 2019-2020 fall semester. Data were collected in two stages. In the first stage, data on variables that might affect preservice teachers' awareness of environmental issues were collected. In the second stage, the main data were collected using the Scale of Awareness of Environmental Issues (SAEI) developed by Güven and Aydoğdu (2012). SAEI consists of 44 items and six subscales: knowledge (eight items), understanding (nine items), application (six items), analysis (eight items), synthesis (seven items), and evaluation (seven items). The total scale has a Cronbach's alpha of .90 while the subscales "knowledge," "understanding," "application," "analysis," "synthesis," and "evaluation" have a Cronbach's alpha of $.95, .95, .91, .90, .75$, and .71 , respectively. The total scale score ranges from 0 to 88, with 0-29 indicating low awareness, 30-59 moderate awareness, and 60-88 high awareness.

For analysis, first, total scores were calculated, and then, statistical analyses were performed for normality testing. The data were not normally distributed, and therefore, non-parametric tests were used for analysis. Frequency, percentage, standard deviation, and arithmetic mean were used for descriptive characteristics. Independent samples Mann Whitney-U and Kruskal Wallis tests were used for between-group comparisons. Data were analyzed using the Statistical Package for Social Sciences (SPSS v. 17) at a significance level of .05.

\section{Result and Discussion}

The results showed that participants were highly aware of environmental issues, which has been reported by previous studies as well (Öcal, 2013; Bülbül \& Y1lmaz, 2019). Participants' level of awareness did not significantly differ by gender, grade level, experiencing environmental issues where they live, and having taken courses on environmental issues. However, participants who attended seminars, meetings or conferences had a significantly higher SAEI score than those who did not. This shows that participants who attended seminars, meetings or conferences were more aware of environmental issues than those who did not, indicating that such events are instrumental in raising social studies preservice teachers' environmental awareness. 